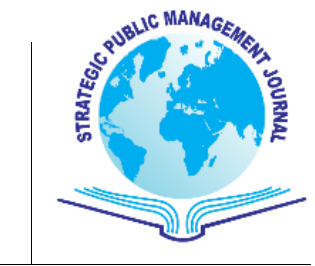

\section{Kentsel Sürdürülebilirlik Kavramı ve Kentsel Sürdürülebilirliğin Sağlanmasında Kent Konseylerinin Rolü Üzerine Bir Değerlendirme ${ }^{1}$}

\author{
An Assessment On The Concept of Urban Sustainability \\ And The Role of City Councils in Ensuring Urban \\ Sustainability
}

\author{
Mustafa KOCAOĞLU \\ Suzan SERT ${ }^{3}$
}

Strategic Public Management Journal Volume 4, Issue 8, pp. XX-XX December 2018 DOI: $10.25069 /$ spmj. 485415 Received: 19.11.2018 Accepted: 28.12 .2018 (C) The Author(s) 2018 For reprints and permissions: http://dergipark.gov.tr/spmj

$\ddot{O} z$

1987 yılında hazırlanmış olan Brundtland Raporu'nda tanımlanmış olan sürdürülebilir kalkınma kavramı, genel olarak, "bugünün ihtiyaçlarının, sonraki nesillerin ihtiyaçlarının karşılanmasına yönelik birikimin riske atılmadan karşılanması” na odaklandiğı görülmektedir. Söz konusu raporda sürdürülebilirlik kavramı ise "yoksulluk ve yoksulluğun çevre üzerindeki tahakkümü", "hızlı nüfus artışının ve nüfus yoğunlaşmasının yaşam kalitesine yönelik olumsuz etkileri”, "çevre kaynaklarının aşır şekilde tüketilmesi" ile "kentsel büyüme ve kentlerin denetimsiz bir şekilde yayılması"na yönelik sorunlar bağlamında ele alınmıştır ve kavram, sürdürülebilir kalkınma ile bu yolla ilişkilendirilmiştir.

Çevre sorunlarını ortadan kaldırmayı ve ekosistemi korumayı amaçlayan kentsel sürdürülebilirlik, sürdürülebilir kalkınmanın yerel düzeyde kentlere uygulanmasıdır. Bu noktada kentsel sürdürülebilirliğin sağlanmasinda yerel yönetimlere önemli görevler yüklenmiştir. Türkiye'de de kentsel sürdürülebilirliğin sağlanmasında yerel yönetimlerin değişen rolüne koşut ve Yerel Gündem 21 uygulamalarının bir sonucu olarak kent konseyi adındaki mekanizmaları oluşturulmuştur.

Bu çalışmada da öncelikle kavramsal ve kuramsal açıdan "sürdürülebilirlik", "sürdürülebilir kalkınma” ve "kentsel sürdürülebilirlik” kavramları ele alınacaktır. Daha sonra, tarihsel süreç içerisinde söz konusu kavramların nasıl bir gelişim seyri içerisinde günümüze geldiği, farklı düzeylerdeki hukuki metinler çerçevesinde ele alınmıştır. Ardından, Türkiye'de kent konseylerinin yapı, kuruluş ve işleyişi ayrıntılı biçimde irdelenecek ve ulusal düzlemdeki hukuki dayanakları üzerinde durulacaktır. Nihayet, kent konseylerinin;

\footnotetext{
${ }^{1} \mathrm{Bu}$ çalışma, 1-3 Kasım 2018 tarihlerinde Alanya'da düzenlenmiş olan 1. Uluslararası Alanya Yerel Yönetimler Sempozyumu'nda sunulmuş ve bildiri kitabında basılmış olan "Sürdürülebilir Kalkınma Ve Kentsel Sürdürülebilirliğin Sağlanmasında Kent Konseylerinin Rolü" isimli çalışmanın yeniden düzenlenmiş ve geliştirilmiş halidir.

2 Assoc. Prof., Necmettin Erbakan University, Faculty of Applied Sciences, Department of Administration, Information Systems, kocaoglumustafa@gmail.com

${ }^{3}$ Graduate Student, AEU Institute of Social Sciences, Department of Political Science and Public Administration, dokuz_eylul1907@hotmail.com
} 
sürdürülebilirlik, sürdürülebilir kalkınma ve kentsel sürdürülebilirlik kavramlarl ile olan ilişkisi ve kent konseylerinin kentsel sürdürülebilirliğin sağlanmasındaki rolü irdelenmiştir.

Anahtar Kelimeler: Sürdürülebilirlik, Sürdürülebilir Kalkınma, Kentsel Sürdürülebilirlik, Kent Konseyleri.

Abstract

The concept of sustainable development, as described in the 1987 Brundtland Report, is generally seen to focus on a meeting the needs of today, without risking the funds for meeting the needs of the next generations. In the report, the concept of sustainability is examined in the context of the issues of the poverty and dominance of poverty on the environment, the negative effects of rapid population growth and population concentration on the quality of life, excessive consumption of environmental resources and urban growth and the uncontrolled spread of cities and the concept is associated with sustainable development by this way.

Urban sustainability, which aims to eliminate environmental problems and protect the ecosystem, is the application of sustainable development to cities at the local level. At this point, local governments have important tasks in achieving urban sustainability. In Turkey, in parallel to the changing role of local authorities in providing urban sustainability and as a result of the Local Agenda 21 applications, mechanisms called the city council were created.

In this study, the concepts of sustainability, sustainable development and urban sustainability will be discussed firstly in terms of conceptual and theoretical aspects. Then, in the historical process, how these concepts have survived in the process of development is discussed within the framework of legal texts at different levels. Then, the structure, establishment and operation of city councils in Turkey will be examined in detail and will be focussed on the legal basis at the national platform. Finally, the city councils' relationship with the concepts of sustainability, sustainable development and urban sustainability and the role of city councils in ensuring urban sustainability will be examined.

Key words: Sustainability, Sustainable Development, Urban Sustainability, City Councils.

\section{GíRiş}

1987 Brundtland Raporu ile "bugünün ihtiyaçlarını, gelecek nesillerin ihtiyaç karşılama kapasitesini riske atmadan karşılamak" şeklinde tanımlanmıştır. Bu raporda, sürdürülebilir kalkınma kavramı üzerinde yoksulluk ve çevre üzerindeki baskıları, nüfusun hızla artması ve yoğunlaşmasının yaşam kalitesinin artmasını engellemesi, çevre kaynaklarının aşırı şekilde tüketilmesi ile kentsel sorun, kentsel büyüme, kentlerin kontrolsüz yayılması gibi sorunlar incelenerek kentsel sürdürülebilirlik vurgulanmıştır. Daha sonra, sürdürülebilir kalkınmanın ve kentsel sürdürülebilirliğin ne olduğu, nasıl sağlanması gerektiği konusunda tarihsel süreçte pek çok çalışma yapılmış ve fikirler ortaya atılmıştır.

Bu minvalde kentsel sürdürülebilirlik ise, sürdürülebilir kalkınma hedeflerinin kentlere uygulanması ile birlikte gerçekleşeceğinden; yerel yönetimlere kentsel sürdürülebilirliği sağlanmada önemli görevler yüklenmiştir. Diğer yandan, gerçekleştirilen Gündem 21 ve/veya Yerel Gündem 21 çalışmaları ile yerel yönetimlerin bu fonksiyonu genişletilmiş ve Türkiye'de kent konseylerinin oluşumuna zemin hazırlanmıştır. 
Bu çalışmada da öncelikle sürdürülebilirlik, sürdürülebilir kalkınma ve kentsel sürdürülebilirlik kavramları kavramsal ve kuramsal olarak açıklanacaktır. Ardından, bu kavramların tarihsel süreçteki gelişimleri ulusal ve uluslararası hukuki metinler çerçevesinde ele alınacaktır. Üçüncü bölümde Türkiye'de kent konseylerinin yapı, kuruluş ve işleyişinden bahsedilecek; ulusal düzlemdeki hukuki dayanakları üzerinde durulacaktır. Çalışmanın önemi ve literatüre olan katkısı ise son bölümde daha net bir şekilde ortaya çıkmaktadır. Çünkü literatürde kent konseyleri ile sürdürülebilirlik ve yerel düzeyde sürdürülebilir kalkınma kavramlarını bir arada kullanan ve aralarındaki ilişkiyi irdeleyen çalışma sayısı son derece sınırlıdır. Bu bağlamda son bölümde kent konseylerinin; sürdürülebilirlik, sürdürülebilir kalkınma ve kentsel sürdürülebilirlik kavramları ile olan ilişkisi üzerinden kentsel sürdürülebilirliğin sağlanmasındaki rolüne değinilmiştir.

\section{SÜRDÜRÜLEBILLIRLIK, SÜRDÜRÜLEBILIIR KALKINMA ve KENTSEL SÜRDÜRÜLEBILIIRLIKK KAVRAMLARINA KURAMSAL BIIR BAKIŞ}

Sürdürülebilirlik, Dünya Çevre ve Kalkınma Komisyonu'nun 1987 yılında yayınladığı Brundtland Raporu ile uluslararası alanda somut bir boyuta kavuşmuştur ve ilk olarak yine bu raporda sürdürülebilir kalkınma, "bugünün ihtiyaçlarını, gelecek kuşakların da kendi ihtiyaçlarını karşılayabilme olanağından ödün vermeksizin karşılamaktır” şeklinde tanımı yapılmıştır. Rapora göre sürdürülebilir kalkınmanın sağlanması için gerekli şartlar şunlardır (Güneş 2004:41):

- Vatandaşların karar almada etkin katılımını destekleyen bir siyasal sistem

- Sürdürülebilir bir şekilde üretim fazlası ve teknik bilgi sağlayabilecek bir ekonomik sistem

- Uyumsuz geliş̧meden doğan gerilimlerin oluşmasını engelleyen bir sosyal sistem

- Gelişme için gerekli ekolojik tabanı korumayı önemseyen bir üretim sistemi

- Durmadan yeni çözümler üretebilecek bir teknolojik sistem

Sürdürülebilir kalkınma yaklaşımı, çevre ile ekonomi politikaları arasında bir uyum sağlanırsa, toplumsal yapıda da bir iyileşme meydana geleceğini savunmaktadır ve sürdürülebilir kalkınmanın "ekonomik sürdürülebilirlik", "sosyal sürdürülebilirlik" ve "çevresel sürdürülebilirlik" olmak üzere üç boyuttan oluştuğu belirtilmiştir (Yazar, 2006:9; Goodland, 1995:17).

Diğer yandan, yüksek okuryazarlık oranı, gelişmiş sağlık hizmetleri, sosyal hizmetlere erişim kolaylığı ve kültürel ve politik katılım mekanizmaları, kentsel yaşam için hayati öneme sahiptir (World Urbanization Prospects, 2014:3). Ayrıca ekonomik kalkınma, yenilik, istihdam, modern yaşam, kadın hakları ve sosyal hareketlilik iyi yönetilen kentlerde daha çok görülür (Cohen, 2006:64). Fakat gerekli altyapının oluşturulamaması ve kent olanaklarının adaletli dağıtılamaması sonucu meydana gelen hızlı ve çarpık kentleşme, sürdürülebilir kalkınmanın önüne geçmeye başlamıştır (World Urbanization Prospects, 2014:3). Bu noktada bir yandan sürdürülebilir kalkınma ile çevresel yaşam kalitesinin, sosyal yaşam kalitesinin ve ekonomik kalkınmanın sağlanması hedeflenirken, diğer yandan "kentsel sürdürülebilirlik" kavramının öne çıktığ1 görülmektedir. Çünkü sürdürülebilir kalkınmayı gerçekleştirecek politikalar, insanların fikir ve eylemlerinin biçimlendiği, yaşadıkları mekânlarda, yani kentlerde uygulanmaktadır. Bu bağlamda Alberti (1996:383) ise sürdürülebilir kentleri, “kent sakinlerinin ihtiyaçlarının yerel ve küresel kaynaklar üzerinde sürdürülebilirliğe uygun olmayan girişimler olmaksızın karşılanması” olarak tanımlamaktadır.

Sürdürülebilir kalkınma ve kentsel sürdürülebilirlik ile ilgili olarak yapılmış olan diğer çalışmalardan bu noktada kısaca bahsetmek uygun olacaktır. Bu bağlamda ilk olarak ifade edilmesi gereken ilk isim Arthur Cecil Pigou'dur. Zenginlik ve Refah (Wealth and Welfare) adlı çalışmasıyla "sürdürülebilirlik" kavramıyla ilgili ilk çalışmayı gerçekleştiren Pigou, insanlığın refahını doğa, insan tarafından üretilen maddeler, insan kaynakları ve bilgi birikimi olmak üzere üç tür sermayeden teşekkül ettiğini ileri sürer. Daha sonra, tarımda kimyasal 
madde kullanımının insan ve çevre üzerindeki olumsuz etkileri üzerinde duran Rachel Carson'un Sessiz Bahar (Silent Spring) adlı çalışması ise 1962 yılında yayınlanmıştır. 1972'de yayınlanan Büyümenin Sınırları (Limits of Growth) adlı kitapta nüfus miktarı, endüstriyel üretim, besin maddeleri, hammadde ve çevre kirliliği arasındaki ilişsiler incelenmiştir (Baker vd.,1997; Carson1962; Pigou,1920'den Akt: Çankır vd. 2012:375376).

Elkington ise 2004 yılında yayımlanmış olan bir çalışmasında "Triple-P"' ya da "triple bottom line" isminde yeni bir sürdürülebilirlik perspektifi geliştirerek sürdürülebilirliği; insan, evren ve kar (people, planet, profit) kavramları çerçevesinde, başka bir söylemle sosyal, çevresel ve ekonomik boyutları ile birlikte ele almıştır. Sürdürülebilirliğin çok boyutlu yapısının daha zengin bir içerikte toparlanarak ele alınmasının önemi üzerinde durur (http://ekoiq.com, 2018).

\section{ULUSAL ve ULUSLARARASI HUKUKİ METİNLERDE SÜRDÜRÜLEBİLİRLIKK, SÜRDÜRÜLEBİLİR KALKINMA ve KENTSEL SÜRDÜRÜLEBİLİRLİK}

Dünya Doğayı Koruma Birliği (IUCN) tarafından 1982 yılında kabul edilen Dünya Doğa Şartı belgesinde "sürdürülebilirlik" kavramı yer almıştır ve belgede ekosistem ve türlerin bütünlüğünü tehlikeye atmadan insanların kullandığı ekosistem, organizmalar, kara, deniz ve atmosfer kaynaklarının en iyi şekilde sürdürülebilirliğini sağlayarak yönetilmelerinin önemi üzerinde durulmuştur (Yazar, 2006:3-4).

Brezilya'nın Rio de Janerio kentinde 1997 yılının Haziran ayında Rio+5 Forumu Rio Konferansı'ndan sonraki 5 y1llık süreçte meydana gelen gelişmeleri değerlendirmek amacıyla gerçekleştirilmiştir. Teknoloji transferini artırma, katılım ve kalkınma için kapasite oluşturma, kurumsal koordinasyon ve aşırı üretim ve tüketim seviyelerini azaltma ile birlikte resmi kalkınma yardımlarının (ODA) düşmesi ve artan uluslararası borç ile yansitılarak sosyal eşitlik ve yoksulluk alanında boşluklar tespit edilmiştir (https://www. sustainabledevelopment2015.org, 2018).

Habitat zirvelerinden ilki, Vancouver'da 1976 yılında gerçekleştirilmiştir. 1996 İstanbul'da yapılan “Habitat II” Zirvesi ile yayınlanan “İstanbul Deklarasyonu” ile katılım gösteren devlet başkanları tarafından "Herkes İçin Yeterli Barınma” ve "Kentleşen Dünyada Sürdürülebilir İnsan Yerleşimleri” "nin oluşturulması adına bir eylem planının uygulanması kararlaştırılmıştır. Habitat III Zirvesi ise, 17-20 Ekim 2016'da Ekvatorun Kito şehrinde gerçekleşmiştir (http://www.idemahaber.com, 2018). Habitat III'ün önemli bir özelliği; Birleşmiş Milletler'in 25 Eylül 2015'te yapılan zirvesinden sonra düzenlenen ilk küresel BM zirvesi olmasıdır. 2015'te "Sürdürülebilir Kalkınma" üzerine yapılan son BM zirvesinde, önümüzdeki 15 yıl zarfında çalışılacak 17 başlık "2030 Sürdürülebilir Kalkınma Hedefleri" olarak ifade edilmiştir (http://www.arkitera.com, 2018).

United Nations 2017 Revision Dünya Nüfus Beklentileri Raporuna göre; her yıl yaklaşık olarak 83 milyon kişi dünya nüfusuna eklenmekte; dünya nüfusunun 2030'a gelindiğinde 8,6 milyar, 2050'de ise 9,8 milyar olacağ tahmin edilmektedir. World Urbanization Prospects (2014) verilerine göre; dünya nüfusunun \%54'ü kentsel alanlarda yaşamaktadır ve giderek daha fazla insanın kentsel alanlarda yaşadığı görülmektedir. 1950'de dünyadaki kentsel nüfus oranı \%30 iken; 2050'ye gelindiğinde bu oranın \%66'ya ulaşacağı beklenmektedir. World Urbanization Prospects (The 2007 Revision) verilerine göre ise; Türkiye nüfusunun 2025 'te 89 milyon 557 bine, 2050'de 98 milyon 946 bine ulaşacağı öngörülmektedir. Hızlı nüfus artışı karşısında kentsel nüfus oranı ülkemizde de geçen yıllara oranla artmaktadır. Türkiye, 1950'den beri hızlı bir şekilde kentleşmektedir. Kentlerde yaşayan nüfus, 1950'de \%25 oranında iken; 2012'ye gelindiğinde bu oran \%77'ye yükselmiştir. 2009 yılında akademisyenler, kamu kurumları temsilcileri ve yerel yetkililer, sivil toplum üyeleri, özel sektör ve odalar Kentleşme Konseyi'nde bir araya gelerek Türkiye'nin sürdürülebilir kentsel kalkınma hedeflerine ulaşması için kentsel gündemi (yerleşimlerin afet dayanıklılı̆̆ı, doğal ve kültürel varlıkların korunması, 
yasadış1 konut, kentsel dönüşüm, teknik ve sosyal altyapı, yaşam kalitesi, yerel kalkınma, kentli vatandaşlık bilinci, yönetişim ve yerel yönetimler) analiz etmişlerdir. Konsey 2010-2023 arası dönemi kapsayan KENTGES Bütünleşik Kentsel Gelişim Stratejisi ve Eylem Planı'nı hazırlamıştır. Plan, 2010'da Yüksek Planlama Kurulu tarafindan kabul edilmiştir. KENTGES, taşımacılık, konut ve arazi temini, afetler, doğal ve kültürel varlıklar, iklim değişikliği, yaşam kalitesi, sosyal politikalar ve katılım gibi kentsel konularında gerçekleştirilecek çalışma ve faaliyetlerde merkezi ve yerel yönetimlere bir yol haritası olarak sunulmuştur (Turkey Habitat-III National Report, 2014).

\section{TÜRKIYY'DE KENT KONSEYLERİ: KURULUŞ, YAPILANMA ve İŞLEYIŞ}

Türkiye'de 1997 yılından itibaren uygulanmaya başlanan Yerel Gündem 21, Kent Konseylerinin oluşmasına da olanak sağlamıştır. Buna bağlı olarak, İçişleri Bakanlığı, Mahalli İdareler Genel Müdürlüğü tarafından “Türkiye' de Yerel Gündem 21 Yönetişim Ağı Kanalıyla BM Binyıl Kalkınma Hedeflerinin Yerelleştirilmesi” projesi ile ilgili bilgi verilmiş, bu projenin 2007 yılında Resmi Gazetede yayınlanarak yürürlüğe girdiği belirtilmiştir. Proje çerçevesinde, kent konseylerinin kapasitelerinin, yerel düzeyde etkin olarak Binyıl Kalkınma Hedeflerine odaklanacak şekilde geliştirilmesi de hedeflenmiştir (Kutlu, Usta ve Kocaoğlu, 2009:519).

Birleşmiş Milletler tarafından Haziran 2007'de Viyana'da (Avusturya) “7. Küresel Forum” düzenlenmiştir ve Türkiye YG-21 Programı kapsamındaki kent konseyi uygulamaları, UNDESA (Birleşmiş Milletler Kamu Yönetimi ve Kalkınma Yönetimi Bölümü) tarafından, "demokratik yönetişim” alanında, dünyadaki en başarılı uygulamalardan biri olarak tanıtılmıştır (Kestellioğlu, 2011:121-140).

Kentteki her kesim ve sektörden bireylerin aynı amaçlar doğrultusunda oluşturdukları bu konseyler, 5393 Sayılı Belediye Kanununun 76. maddesinde de belirtildiği üzere, "kent yaşamında; kent vizyonunun ve hemşehrilik bilincinin geliştirilmesi, kentin hak ve hukukunun korunması, saydamlık, hesap verme, sürdürülebilir kalkınma, çevre duyarlılığı, sosyal yardımlaşma ve dayanışma, katılım ve yerinden yönetim ilkelerini hayata geçirme" ilkelerini gerçekleştirmek amaciyla kurulmuştur (Kocaoğlu, 2015:109). Yürütme yetkisi olmayan; yalnızca "danışma” özelliği taşıyan bir sistem olan kent konseylerinde muhtarlar, kamu-özel sektör kurum ve kuruluş temsilcileri, sendikalar, üniversiteler ve uzman kişiler kent konseyine katılabilecek aktörlerdir (Çukurçayır, 2011:49).

5393 sayılı Belediye Yasası ile yerel yönetimde katılım ve demokrasiyi güçlendirmek amacıyla belediyelere "kent konseyi” adındaki mekanizmaları oluşturma yetkisi verilmiştir (Aygen, 2014: 218).

8 Ekim 2006 tarihli Kent Konseyi Yönetmeliği'nin 1. maddesinde bu yönetmeliğin amacı; "Kent yaşamında, kent vizyonunun ve hemşehrilik bilincinin geliştirilmesi, kentin hak ve hukukunun korunması, sürdürülebilir kalkınma, çevreye duyarlılık, sosyal yardımlaşma ve dayanışma, saydamlık, hesap sorma ve hesap verme, katılım, yönetişim ve yerinden yönetim ilkelerini hayata geçirmeye çalışan kent konseylerinin çalışma usul ve esaslarını düzenlemektir.” şeklinde ifade edilir.

Kent konseyinde oluşturulan görüşler belediye meclisinin ilk toplantısında gündeme alınarak değerlendirilir. İlgili yönetmeliğin 6 . maddesinin 1 . bendinde kent konseylerinin görevleri açıklanmıştır (http://www.resmigazete.gov.tr, 2018) :

a) Yerel düzeyde demokratik katılımın yaygınlaştırılmasını, hemşehrilik hukuku ve ortak yaşam bilincinin geliştirilmesini, çok ortaklı ve çok aktörlü yönetişim anlayışının benimsenmesini sağlamak, 
b) (Değişik bend: 06/06/2009 - 27250 S.R.G Yön./2. mad.) Sürdürülebilir gelişmenin sağlanmas1 ve bu konuda ortaya çıan sorunların çözümüne yönelik planların hazırlanması ve uygulanmasını sağlamak (http://www.resmigazete.gov.tr, 2018),

c) Kente ilişkin temel stratejiler ve faaliyet planlarının belirlenmesinde, uygulama ve izleme süreçlerinde tüm kenti kapsayan ortak bir aklın oluşturmasına katkıda bulunmak,

d) Yerellik ilkesi çerçevesinde katılımcılığı, demokrasiyi ve uzlaşma kültürünü geliştirmek,

e) Kentin kimliğine ilişkin tarihi, kültürel, doğal ve benzeri değerlere sahip çıkmak ve geliştirmek,

f) Kent kaynaklarının etkili, verimli ve adil kullanımına katkıda bulunmak,

g) Sürdürülebilir kalkınma anlayışına dayalı kentin yaşam kalitesini geliştiren, çevreye duyarlı ve yoksulluğu giderici programları desteklemek,

h) Sivil toplumun gelişmesine ve kurumsallaşmasına katkıda bulunmak,

i) Çocukların, gençlerin, kadınların ve engellilerin toplumsal yaşamdaki etkinliklerini arttırmak ve yerel karar alma mekanizmalarında aktif rol almalarını sağlamak,

j) Kent yönetiminde saydamlık, katılım, hesap verebilirlik, öngörülebilirlik ilkelerinin uygulanmasına katkıda bulunmak,

k) Kent konseyinde oluşturulan görüşlerin değerlendirilmek üzere ilgili belediyeye gönderilmesini sağlamaktır."

Kent Konseyleri belediye teşkilatı olan yerlerde, mahalli idareler genel seçim sonuçlarını izleyen 3 ay içinde kurulur ve 8 inci maddede belirtilen üyelerden oluşmaktadır. Kent konseyi genel kurulu ilk toplantısı için belediye başkanının çağrısı ile toplanır. Belediye başkanının başkanlığında toplanan genel kurul, toplantıyı idare etmek üzere üyeleri arasından en az üç kişiden oluşan divan kurulunu seçer. Divan kurulunun oluşturulmasından sonra, kent konseyi yürütme kurulu ve kent konseyi başkanı seçilir. Kent konseylerinin organları yönetmelikte genel kurul, yürütme kurulu, meclisler ve çalışma grupları, kent konseyi başkanı olarak sıralanmıştır (http://www.resmigazete.gov.tr, 2018).

\section{ULUSAL ve ULUSLARARASI METINLERDE KENTSEL SÜRDÜRÜLEBİLİRLİĞIN SAĞLANMASINDA KENT KONSEYLERININN ROLÜ}

1992 Rio Yeryüzü Zirvesi sonunda “İnsanlık, tarihsel bir dönüm noktasındadır.” cümlesi ile başlayan Gündem 21 kabul edilerek sürdürülebilir kalkınma hedeflerine yönelik ilke ve eylemler belirlenmiştir. Gündem 21 ile yerel yönetimler; ortaklıklar ve katılım, ilgili kuruluşlar olarak çeşitli faaliyetlerde bulunma, çevresel meseleleri (sulak alanların korunması, deniz ve hava kirliliği, zehirli atıkların denetimi, iklim değişikliği, biyolojik çeşitliliğin korunması...) içerisine alam taahhüt belgeleri kapsamında üstlendikleri roller ile uluslararası yerel yönetim kuruluşları aracılığı ve direkt olarak uluslararası işbirliği ve dayanışma faaliyetlerini yürütme şeklinde dört alanda etkinlik göstermektedirler. Gündem 21'in sürdürülebilir kalkınmanın yerel düzeyde hedeflerini gerçekleştirecek Yerel Gündem 21 farklı türde katılımcı modelini hayata geçirmek için yerel ortaklıklara dayalı yönetişim anlayışıdır. UNDP, Türkiye'deki Yerel Gündem 21 uygulamalarını 2001 senesinde dünyada en başarılı örneklerden biri olarak göstermiş̧tir (Emrealp, 2005:16,20,33).

Katılımcı demokrasi ile çevre ve yaşam kalitesini geliştirmek için BM Kalkınma Programı ile kolektif bir şekilde hayata geçirilmeye çalışılan Yerel Gündem 21, 1997'den bu tarafa yönetişimde başarı arayışı içerisinde “sessiz devrim” olarak da nitelendirilmektedir. Yerel Gündem 21 uygulamaları, Türkiye'de 1997'nin sonundan 
itibaren "Türkiye'de Yerel Gündem 21'lerin Teşviki ve Geliştirilmesi” Projesi ile hız kazanmıştır (http://www.mfa.gov.tr, 2018).

Kentteki her kesim ve sektörden bireylerin aynı amaçlar doğrultusunda oluşturdukları bu konseyler, 5393 Sayılı Belediye Kanununun 76. maddesinde de belirtildiği üzere, "kent yaşamında; kent vizyonunun ve hemşehrilik bilincinin geliştirilmesi, kentin hak ve hukukunun korunması, saydamlık, hesap verme, sürdürülebilir kalkınma, çevre duyarlılığı, sosyal yardımlaşma ve dayanışma, katılım ve yerinden yönetim ilkelerini hayata geçirme" ilkelerini gerçekleştirmek amacıyla kurulmuştur (Kocaoğlu, 2015:109). Yürütme yetkisi olmayan; yalnızca "danışma" özelliği taşıyan bir sistem olan kent konseylerinde muhtarlar, kamu-özel sektör kurum ve kuruluş temsilcileri, sendikalar, üniversiteler ve uzman kişiler kent konseyine katılabilecek aktörlerdir (Çukurçayır, 2011:49).

Kentin yaşanabilir hale gelmesi için kent konseylerine 4 önemli görev yüklenmiştir : Kentte yaşayanlar tarafından kentin hak ve hukukunun korunması, kent konseyinin kentte yaşayan insanlar arasında sosyal yardımlaşma ve dayanışmayı artırma, sürdürülebilir kalkınma konusunda hemşehrilerde bilinç oluşturulması, yerel düzeyde hesap verme, hesap sorma, katılım ve yönetişimin gerçekleştirilmesi (Özcan ve Yurttaş, 2010: 168-169).

Belediye Kanunu'nda yer alan Kent Konseyleri ile ilgili maddeden (madde 76) ve bu maddede kent konseylerine yüklenen görevlerden de anlaşılacağı üzere kent konseylerinin sürdürülebilir kalkınma ve dolayısıyla kentsel sürdürülebilirliğin sağlanmasında önemli bir rol üstlendiği görülmektedir. Buna koşut olarak 2006 yılında çıkarılan Kent Konseyi Yönetmeliği'nde ise sürdürülebilir kalkınma ve kentsel sürdürülebilirlik ile ilgili olarak pek çok ifade yer almaktadır. Buna göre sürdürülebilir kalkınmaya öncelikle, amaç, kapsam, dayanak ve tanımlar başlığı altındaki 1. bölümün, 1 ve 4. maddelerinde yer verilmiştir. Ayrıca, yönetmeliğin, kent konseylerinin görevlerinin düzenlendiği 6. maddesinin "b" ve "f" fikralarında sürdürülebilir kalkınma ifadesi geçmektedir. Bu fikralarda kent konseylerine "sürdürülebilir gelişme sorunlarının çözümüne yönelik uzun dönemli bir planın hazırlanması ve uygulanmasını sağlamak" ve "sürdürülebilir kalkınma anlayışına dayalı, kentin kalitesini geliştiren, çevreye duyarlı ve yoksulluğu giderici programları desteklemek" görevleri verilmiştir. Bununla birlikte, çalışma ilkelerinin düzenlendiği 7. maddenin "c" fikrasında sürdürülebilir kalkınma kavramı, uyulması gereken bir ilke olarak gösterilmiş ve bu ilke doğrultusunda çalışmalar yapılması gerektiği belirtilmiştir. Böylece sürdürülebilir kalkınma, gerek kanun, gerekse de yönetmelik hükümleri doğrultusunda kent konseyleri açısından bağlayıcı ve belirleyici bir konuma gelmiştir (Kocaoğlu, 2015:109).

\section{SONUÇ}

Sürdürülebilirlik konusunda tarihsel süreç içerisinde yapılmış olan çalışmalar, çevresel politikalarla ekonomi politikalarının uyum içerisinde olması gerekliliğinin aslında, kent yaşamında karşılaşılan olumsuzlukların ve kentleşme sorunlarının bir sonucu olduğunu göstermiştir. Dünya nüfusu beklentileri konusunda hazırlanan raporlar incelendiğinde ise gelecekte nüfus artışı ile birlikte kentsel nüfus oranının da büyük ölçüde yükseleceği öngörüsüne ulaşılmaktadır. Buradan hareketle; kentlerin sürdürülebilirliğinin sağlanması, bugün olduğu gibi gelecek kuşaklar için de hayati bir öneme sahip olacaktır. 
Kentsel sürdürülebilirlik, sürdürülebilirliğin kentlerin ekonomik, sosyal ve çevresel ihtiyaçları ve yükümlüklerini göz önünde tutarak yerel yönetimlerin, merkezi yönetim, özel sektör, sivil toplum kuruluşları, vatandaşlar ve diğer tüm kesimlerle işbirliği içerisinde olacak şekilde kentlerde uygulanmasını sağlayacak bir mekanizma olan kent konseylerinin teşekkül etmesine zemin hazırlamıştır.

Yerel yönetimlerin üstlendiği bu önemli sorumluluk, Rio Konferansı'nda hazırlanan Gündem 21 ile vurgulanmıştır. 1997'den itibaren Türkiye'de de uygulanmaya başlanan YG-21 programının ardından 2005 tarih ve 5393 sayılı yeni Belediye Kanunu ile kent konseylerinin hukuki statüsü belirlenmiştir. Böylelikle belediyelere kent konseyi oluşturma yetkisi verilmiş; 2006 Kent Konseyi Yönetmeliği ile kent konseylerinin görevleri sürdürülebilirlik ve kentsel sürdürülebilirlik kavramlarıyla desteklenmiştir.

Kent konseyleri, vatandaş isteklerini ve düşüncelerini göz önüne alarak ve yerel yönetimlerin faaliyetlerini halk ve merkezi yönetim arasında bağlantı kurarak gerçekleştirmeyi amaçlayan mekanizmalardır. Dolayısıyla kuruluş amacı; tamamen kentsel yaşam kalitesinin ve yerel demokrasinin gelişmesine katkı sağlamak olan bu mekanizmalara, kentleri sürdürülebilir insan yerleşkesine dönüştürmede yaşamsal sorumluluklar yüklenmiştir. $\mathrm{Bu}$ bağlamda kent konseyleri, ilgili mevzuat hükümleri ve sürdürülebilir kalkınmaya yönelik uygulama ölçütlerinden de anlaş1lacağ üzere, bir kentteki kalkınmaya yönelik tüm sorunlara, merkezi yönetim, yerel yönetim, sivil toplum kuruluşları, vatandaşlar ve doğrudan veya dolaylı diğer tüm kesimleri bir araya getirerek işbirliği ve dayanışma içerisinde sürdürülebilir çözümler bulmalarına aracılık eden, yerel düzeyde yönetişim ilkelerinin geçerli kılındığı aktif ve dinamik bir yapı özelliği göstermektedir. Dolayısıyla yerel düzeyde katılım ve demokrasiyi güçlendirecek mekanizmalar olarak görülen kent konseyleri, kentsel sürdürülebilirliği sağlamada yerel yönetişimin bir omurgasını teşkil etmektedir. 


\section{KAYNAKÇA}

Alberti, M. (1996), “Measuring Urban Sustainability”, Environ Impact Assess Rev., C. 16, ss. 381-424.

Aygen, M. (2014), “An Investigation of The Contributions of City Councils to The Urban Management: Elaziğ Sample”, International Journal of Social Science, C.29, ss.217-236.

Cohen, B. (2006), "Urbanization in Developing Countries: Current Trends, Future Projections and Key Challenges for Sustainability”, Technology in Society, C. 28, ss.63-80.

Çankır, B., Fındık, H. ve Koçak, Ö. E. (2012), "Sürdürülebilirlik ve Sürdürülebilir Organizasyon Yönetimi”, $1^{\text {st }}$ International Conference on Sustainable Business and Transitions for Sustainable Development Bildiriler Kitabl, ss.375-385.

Çukurçayir, M. A. (2011), Yerel Yönetimler: Kuram, Kurum ve Yeni Yaklaşımlar, Çizgi Kitabevi, Konya.

Emrealp, S. (2005), Yerel Gündem 21 Uygulamalarına Yönelik Kolaylaştırıcı Bilgiler El Kitabı, Birmat Matbaası, İstanbul.

Goodland, R. (1995), "The Concept of Environmental Sustainability", Annual Review of Ecology and Systemaics, C. 26, ss.1-24.

Güneş, M. (2004), Yerel Gündem 21 "Ulusal” Kentlerden “Küresel” Köylere, Detay Yayıncılık, Ankara. https://www.sustainabledevelopment2015.org/AdvocacyToolkit/index.php/earth-summit-history/past-earthsummits/60-rio-1997 (25/06/2018).

http://www.idemahaber.com/habitat-iii-konferansi-2016-yilinda-ekvatorda/ (25/06/2018).

http://www.arkitera.com/haber/27733/habitat-iii (25/06/2018).

http://resmigazete.gov.tr/eskiler/2006/10/20061008-5.htm (25/06/2018).

http://www.resmigazete.gov.tr/eskiler/2009/06/20090606-9.htm (25/06/2018).

http://www.mfa.gov.tr/yerel-gundem-21.tr.mfa (26/06/2018).

http://ekoiq.com/2013/11/27/uclu-bilanco-sistemi/ (25/06/2018).

Kestellioğlu, G. (2011), "Yerel Demokrasi ve Kent Konseyleri: Kahraman Maraş Örneği”, Kahramanmaraş Sütçü İmam Üniversitesi İ̈BF Dergisi, C. 1, S.1, ss. 121-140.

Kocaoğlu, M. (2015), "Yerel Sürdürülebilir Kalkınma ve Kent Konseyleri: Kırşehir Kent Konseyi Örneği Üzerinden Uygulamalı Bir Çalışma", Paradoks Ekonomi, Sosyoloji ve Politika Dergisi, C.11, S.2, ss. 110-113.

Kutlu, Ö., Usta, S., Kocaoğlu, M. (2009), "Vatandaş Odakl1/Vatandaşın Odakta Olduğu Yönetim: Kent Konseyleri ve Selçuklu Belediyesi Örneği”, Sosyal ve Ekonomik Araştırmalar Dergisi, C. 9, S.18, ss. 507-532.

Özcan L. ve Yurttaş, F. (2010), "Kent Konseyleri Müzakereci Demokrasinin Uygulama Alanı Olarak Düşünülebilir mi?”, Yerel Yönetimler Yerel Siyaset ve Kentsel Politikalar, (Edt. Bekir Parlak), Dora Yayınc1lık, Bursa.

Turkey Habitat-III National Report (2014), "Republic of Turkey Ministry of Environment and Urbanization”, Ankara.

World Population Prospects (2017), “The 2017 Revision”, United Nation, New York. 
World Urbanization Prospects (2007), "The 2007 Revision”, United Nations Department of Economic and Social Affairs/Population Division.

World Urbanization Prospects (2014). “The 2014 Revision”, U.N. Department of Economic and Social Affairs. New York.

Yazar, K. Hakan (2006). "Sürdürülebilir Kentsel Gelişme Çerçevesinde Orta Ölçekli Kentlere Dönük Kent Planlama Yöntem Önerisi”. Ankara Üniversitesi Sosyal Bilimler Enstitüsü Yayınlanmamış Doktora Tezi. 